\author{
Erwin J. O. Kompanje \\ Yorick de Groot
}

\section{Immanuel Kant's categorical imperative and the brain-dead patient}

Accepted: 19 March 2015

Published online: 30 April 2015

(C) Springer-Verlag Berlin Heidelberg and ESICM 2015

\section{Dear Editor,}

In a response to our arguments why we think that mandatory retrieval of organs for transplantation is unacceptable [1], Lazaridis [2] approached the problem from three dominant moral theories: consequentialism, contractualism and especially from Kantianism. Such an approach is mostly theoretical and it always difficult to defend modern concepts such as brain death and modern practice such as organ transplantation by referring to the ideas of an eighteenth century philosopher like Immanuel Kant (1724-1804). However, Kant believed that if an action is not done with the motive of duty, then it is without moral value. His categorical imperative (CI) is the way in which you determine what your duties are, what you should and should not do. It is categorical, as it applies to everyone, without exception. The second formulation of the CI is "Act in such a way that you treat humanity, whether in your own person or in the person of another, always at the same time as an end and never simply as a means'. People are 'ends in themselves' and have intrinsic value, not mere instrumental value. Treating patients solely as a means, e.g. treating patients solely as an instrument to obtain something for yourself, such as organs, fails Kant's test. In virtue of being a human being, a person has rights, dignity, and intrinsic moral worth and value.

Lazaridis valued a brain-dead patient as an 'organism', and a 'nonperson', in this way escaping the rules of the CI. Because, according to Lazaridis, a brain-dead patient is not a person anymore, there is no one to be treated as a means anymore. There is no 'rational agent' to respect anymore. The reason why we think that mandatory retrieval of organs from brain-dead patients is never acceptable is that it is not self-evident to all persons that brain-dead patients are dead. There are just too many signs of life; as an example, we mention the pregnant brain-dead woman who is treated on an intensive care unit for months. It is very difficult for everybody to see such a pregnant braindead woman as a 'non-person' or just an impersonal 'organism' with a developing child inside her womb. Furthermore, a patient in a persistent vegetative state is also not regarded as a 'rational agent' anymore, but is not categorically treated as an 'organism' or a 'non-person', not deserving our respect, although some think that they are even 'more dead than dead' [3] and others think they should be used as organs donors [4].

As the CI is categorical, and thus has to apply to everyone, without exception, it is not applicable to the brain-dead patient because not all judge, on the basis of plausible arguments, a brain-dead to be a dead 'non-person'.

\section{References}

1. Kompanje EJ, de Groot YJ (2015) Sounding board: is mandatory recovery of organs for transplantation acceptable? Intensive Care Med. doi: 10.1007/s00134-015-3681-9

2. Lazaridis C (2015) Routine recovery of organs for transplantation can be acceptable. Intensive Care Med. doi: 10.1007/s00134-015-3739-8

3. Gray K, Knickman TA, Wegner DM (2011) More dead than dead: perceptions of persons in the persistent vegetative state. Cognition 121:275-280

4. Hoffenberg R, Lock M, Tilney $\mathrm{N}$ et al (1997) Should organs from patients in permanent vegetative state be used for transplantation? Lancet 350:1320-1321

E. J. O. Kompanje (®) · Y. de Groot Rotterdam, The Netherlands e-mail: e.j.o.kompanje@erasmusmc.nl 